\title{
Change-Channel Angular Extrusion of Magnesium Alloy AZ31
}

\author{
Tianmo Liu ${ }^{1,2, *}$, Jianzhong Liu ${ }^{1,2}$, Liwei $\mathrm{Lu}^{1,2}$, Yu Liu ${ }^{1,2}$ and Zhongchang Wang ${ }^{3, *}$ \\ ${ }^{1}$ College of Materials Science and Engineering, Chongqing University, Chongqing 400044, P. R. China \\ ${ }^{2}$ National Engineering Research Center for Magnesium Alloys, Chongqing University, Chongqing 400044, P. R. China \\ ${ }^{3}$ WPI Research Center, Advanced Institute for Materials Research, Tohoku University, Sendai 980-8577, Japan
}

\begin{abstract}
We report microstructure evolution and mechanical properties of $\mathrm{Mg}$ alloy AZ31 processed by a new severe plastic deformation technique, the change-channel angular extrusion (CCAE). Under all of the processing temperatures ranging from 523 to $723 \mathrm{~K}$, grains of the extruded Mg alloys are found to be refined significantly, which is attributed to the grain subdivision and dynamic recrystallization induced by the drastic deformation. We have also found that lowering processing temperature is a relevant factor in yielding finer grain, which as a consequence, gives rise to higher micro-hardness, larger yield and ultimate compressive strength, and more enhanced compressive ratio. The improved mechanical properties of the AZ31 alloys deformed by the CCAE are comparable or even superior to those of the alloys subjected to the equal-channel angular extrusion with several passes, rendering the CCAE an effective and promising approach to impose drastic plastic deformation for further enhancing workability of Mg alloys. [doi:10.2320/matertrans.MRA2008429]
\end{abstract}

(Received November 20, 2008; Accepted January 23, 2009; Published March 18, 2009)

Keywords: change-channel angular extrusion, AZ31 magnesium alloy, microstructure evolution, mechanical property

\section{Introduction}

The continuous fighting against energy consumption and environment degradation, together with increasing shortage of natural resources, is making it indispensable to produce and employ a broad range of light-weight metallic alloys where weight savings directly lower costs and increase efficiencies. ${ }^{1,2)}$ To date, magnesium alloys are the lightest structural alloys and thus very attractive in a variety of technical applications, ${ }^{3)}$ especially in automotive, aircraft industries, and electronic sectors. One of the key technology issues hindering the wide use of $\mathrm{Mg}$ alloy as a structural material is its poor formability and restricted ductility, owing primarily to its hexagonal close packed (HCP) crystal structure and consequent limitation on number of available slip systems. ${ }^{4)}$ To improve the plastic workability of $\mathrm{Mg}$ alloy, change of crystal structure by addition of $\mathrm{Li}^{5,6)}$ or grain refining through adulterating foreign atoms ${ }^{7}$ has been attempted. However, these approaches rely critically on the chemical composition of alloys, resulting in restrained level of enhancement.

Recently, another technique, severe plastic deformation (SPD) ${ }^{8,9)}$ has emerged as a promising processing fashion to tailor fine-grained microstructure for improving ductility, strength, and superplasticity. Of all the well-known methods to provide the SPD, the equal-channel angular extrusion (ECAE) or equal-channel angular pressing (ECAP) appears to be one of the most effective ones to acquire bulk ultrafine grained materials without residual porosity and significant change of geometrical shape of the sample. ${ }^{10)}$ The idea of this process is quite simple: a billet is pushed through an angular die having two channels of identical cross sections that intersect at an angle, usually right angle, several times. ${ }^{11,12)}$ Under repeated high pressure torsion, a large shear strain can be accumulated in the billet, inducing structural refinement, which ultimately leads to improved mechanical properties.

*Corresponding author, E-mail: tmliu@cqu.edu.cn, zcwang@wpi-aimr. tohoku.ac.jp
Using this ECAE deformation on Mg alloy AZ31, Janecek et al. ${ }^{13)}$ reported that grain size can be reduced by a factor of $100 \sim 200$ after four passes at $200^{\circ} \mathrm{C}$, resulting in significant increase of room-temperature yield strength. In addition, $\mathrm{Su}$ et al. ${ }^{14)}$ showed that the grain size of AZ31 alloy can be refined noticeably as number of treatment pass increases. A grain size of approximately $1.9 \mu \mathrm{m}$ can be obtained after four passes at $220^{\circ} \mathrm{C}$, accompanied by enhanced yield strength but lowered ductility. Further, Jin et al. ${ }^{15)}$ applied a two-step ECAE process and obtained ultrafine grain size of $0.5 \mu \mathrm{m}$, which consequently increases both yield stress and ductility. These are but a few representative examples to exhibit evidently that several passes are needed for the ECAE before acquiring fine grains, and that variation in processing conditions may yield a wide change of microstructures, thereby altering or improving mechanical properties.

In this work, we proposed a modified ECAE process, change-channel angular extrusion (CCAE), in order to introduce even more severe plastic deformation so as to reduce the number of pass. We tested this CCAE technique on $\mathrm{Mg}$ alloy AZ31, aiming to reveal microstructure evolution and how it affects mechanical properties during the CCAE experiments. As an initial step to apply this approach, we focused only on elevated processing temperatures ranging from 523 to $723 \mathrm{~K}$ to help avoid cracking formation and propagation. The second goal of this work is to discuss underlying grain refining mechanism during the CCAE process and to compare behaviors of CCAE-processed alloys with those of the alloys that undergo ECAE processing.

\section{Experimental Procedure}

The material used in this study was a commercial $\mathrm{Mg}$ alloy AZ31 with the following composition (in mass \%): $3 \% \mathrm{Al}$, $1 \% \mathrm{Zn}, 0.3 \% \mathrm{Mn}$, and $\mathrm{Mg}$ (balance), supplied in form of cast ingots. The ingots were machined into cylindrical samples with a cross-section dimension of $\phi 30 \mathrm{~mm} \times 60 \mathrm{~mm}$ and then homogenized as starting materials for the CCAE processing. The CCAE was carried out through a die with 


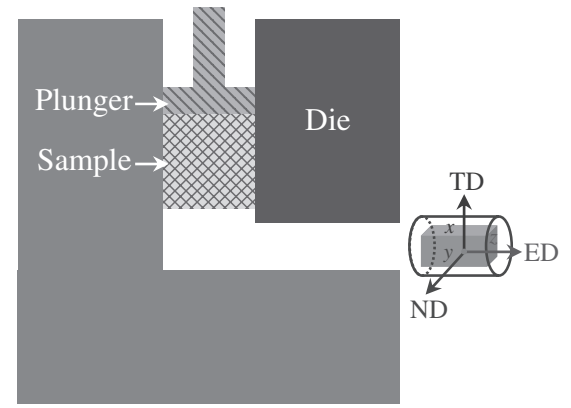

Fig. 1 A schematic diagram of the change-channel angular extrusion process. In contrast to the identical channels in the ECAE, the vertical channel in the CCAE is larger than the horizontal one. The ED, ND and TD represent the extrusion direction, normal direction, and transverse direction, respectively.

an internal angle of $90^{\circ}$ between vertical and horizontal channels that have different cross sections, as schematically illustrated in Fig. 1. The fully lubricated die was preheated to and stabilized at $523 \mathrm{~K}, 573 \mathrm{~K}, 623 \mathrm{~K}, 673 \mathrm{~K}$, and $723 \mathrm{~K}$, respectively, before samples were inserted into the entrance channel. The heated samples were first held in the die for 20 min to keep the same temperature as the die and then extruded once using a velocity of $2.5 \mathrm{~mm} / \mathrm{min}$ and extrusion ratio of 4 to produce rods with diameters of $15 \mathrm{~mm}$.

Microstructures of the samples were examined using optical microscopy (OM) and transmission electron microscopy (TEM). For the OM, samples were cut and mounted in transparent epoxy, followed by mechanical polishing with $6 \mu \mathrm{m}$ and $1 \mu \mathrm{m}$ diamond paste and short final polishing using colloidal silica. Subsequent etching using a solution of $5 \mathrm{~g}$ picric acid dissolved in $10 \mathrm{ml}$ water, $5 \mathrm{ml}$ acetic acid, and $100 \mathrm{ml}$ ethanol revealed the grain structure. The mean grain size from the optical micrographs was determined by following the procedures given in ASTM standard E11295. As for the TEM, specimens were first cut from corner sections of the pressed billets vertical to pressing direction and then mechanically polished to thin foils. The foils were finally electropolished using a Tenupol 5 double jet polishing unit in a solution of $\mathrm{LiCl}, \mathrm{Mg}$ perchlorate, methanol, and buthyloxyethanol at $228 \mathrm{~K}$. The prepared specimens were investigated using a Philips TECNAI-20 electron microscope operated at $200 \mathrm{kV}$. Compressive experiments were carried out at room temperature with a speed of $2 \mathrm{~mm} / \mathrm{min}$ using specimens having diameter and length of 10 and $20 \mathrm{~mm}$, respectively, cut along the longitudinal direction of the CCAE-processed billets. The Vickers hardness $\left(H_{\mathrm{V}}\right)$ was measured using a micro-hardness indenter at a load of $0.49 \mathrm{~N}$ for $20 \mathrm{~s}$.

\section{Results and Discussion}

\subsection{Microstructure characteristics}

Optical microstructures of the as-cast AZ31 specimen and its homogenized one before CCAE are shown in Fig. 2. The average grain size of the AZ31 alloy provided in the form of cast ingots is approximately $100-140 \mu \mathrm{m}$, while that of the homogenized alloy is about $120-150 \mu \mathrm{m}$, which shows that grains are somewhat coarsened by homogenization. Additionally, it is apparent that the grains in both cases are not uniformly distributed, even for the homogenized specimen (Fig. 2(b)), having fine grains of less than $30 \mu \mathrm{m}$ and coarse ones of over $200 \mu \mathrm{m}$. The density of dislocations, however, seems to be reduced after homogenization. The visible uneven microstructure can be greatly improved after a CCAE processing since initial coarse grains are replaced pronouncedly by newly generated equiaxed fine ones, as presented in Fig. 3. This clearly shows that like the ECAE, the grain size can also be affected or refined by the CCAE.

The mean grain sizes of the AZ31 samples deformed by the CCAE at different temperatures ranging from 523 to $723 \mathrm{~K}$ by a step of $50 \mathrm{~K}$ are determined to be $9,15,23,26$, and $33 \mu \mathrm{m}$, respectively, as illustrated in Figs. 3(a)-3(e). The grain size increases in an order of raising processing temperature, indicating that the processing temperature is a relevant factor in controlling microstructure of AZ31 alloy. That is, the lower processing temperature, the finer grain size. This is in accordance with the results in previous reports on AZ31 alloy treated by the ECAE process ${ }^{15,16)}$ and asymmetrical rolling technique. ${ }^{17)}$ From Fig. 3, one can also see that grains in the alloy processed at each temperature are much more evenly distributed compared to those in the ascast alloy (Fig. 2), suggesting that dynamic recrystallization occurs during the CCAE process. However, even for the most significant grain refinement at $523 \mathrm{~K}$ (Fig. 3(a)), the microstructure is still not fully homogeneous, consisting of fine grains of $\sim 6 \mu \mathrm{m}$ and coarse ones of $\sim 15 \mu \mathrm{m}$, which implies
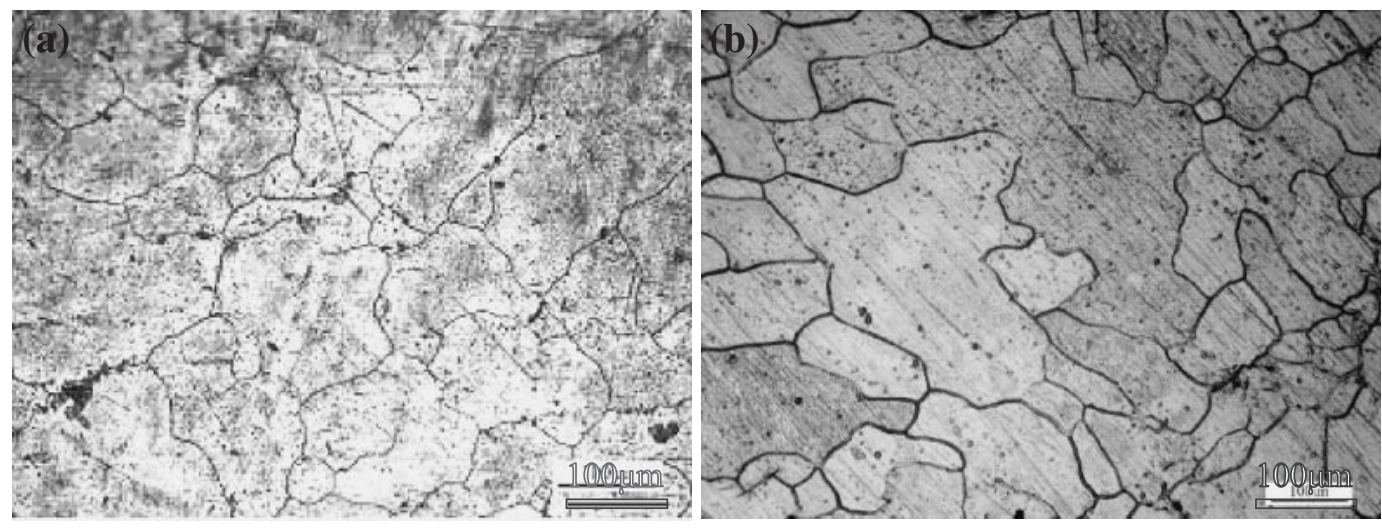

Fig. 2 Optical microstructures of the AZ31 alloys before CCAE processing: (a) as-cast and (b) homogenized at $673 \mathrm{~K}$. 

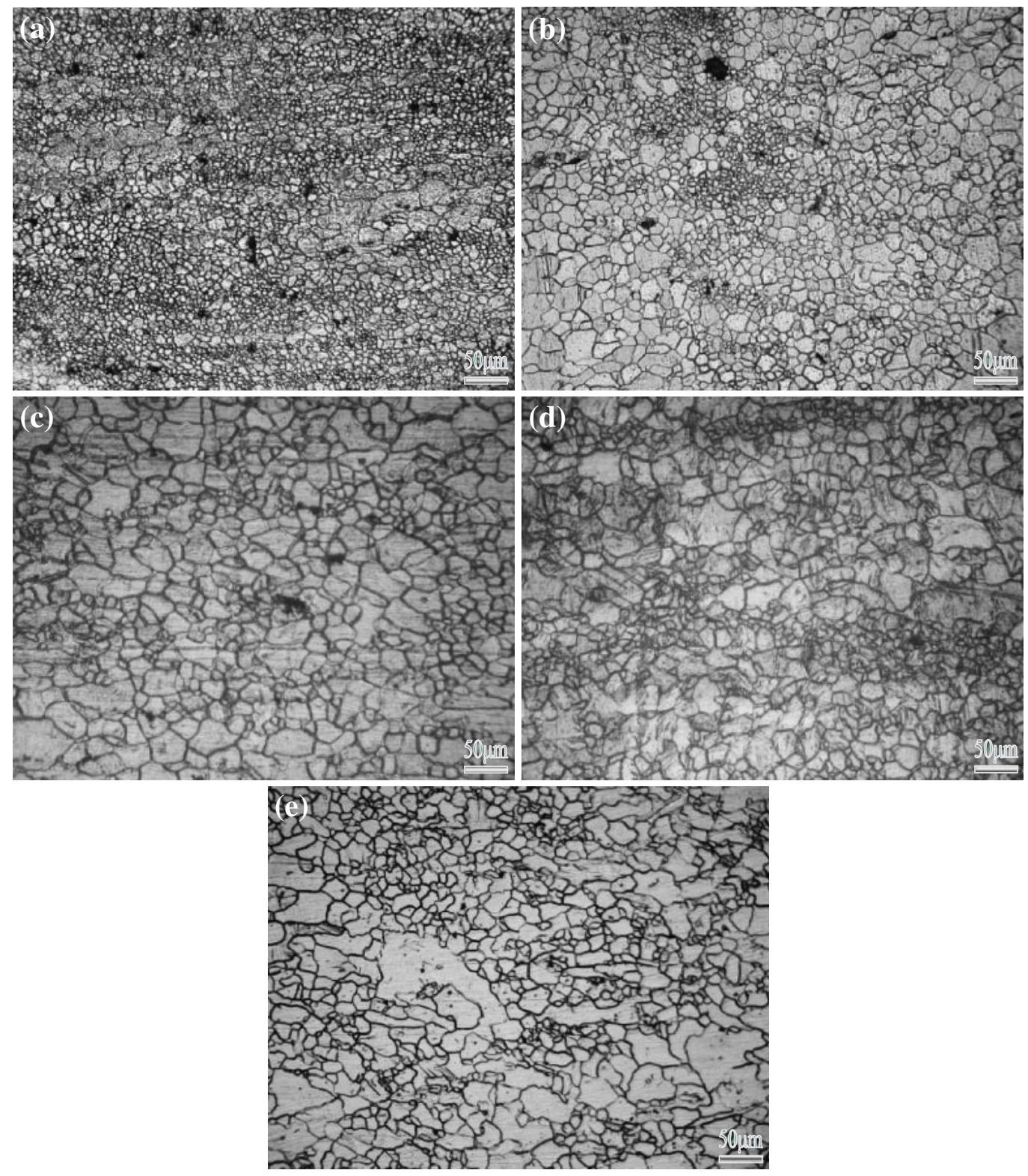

Fig. 3 Optical micrographs of the AZ31 alloys processed by the CCAE at (a) $523 \mathrm{~K}$, (b) $573 \mathrm{~K}$, (c) $623 \mathrm{~K}$, (d) $673 \mathrm{~K}$, and (e) $723 \mathrm{~K}$.

that the recrystallization is not totally completed. It is noteworthy that unlike the reports that ultrafine grains of smaller than $1 \mu \mathrm{m}$ in the AZ31 alloy can be obtained by 8 repetitive ECAEs ${ }^{18)}$ or two-step ECAE ${ }^{15}$ ) the grain size in our CCAE-processed alloy seems to be much larger. This is mainly because of the high processing temperature we used, higher than half of the melting temperature $T_{\mathrm{m}}$, so that dynamic recrystallization and grain growth take place, ${ }^{19)}$ and also because of the only one pass. Further refinement of grains is still in progress. Nevertheless, we have noticed that our average grain size of $9 \mu \mathrm{m}$ at $523 \mathrm{~K}$ is somewhat smaller than that of $10.5 \mu \mathrm{m}$ deformed once by the ECAE at $493 \mathrm{~K}^{14)}$ and much less than that of $17 \mu \mathrm{m}$ after two-pass ECAE at $473 \mathrm{~K}^{20)}$

To gain insight into the microstructure in more details and how it evolves as the samples are deformed by shearing, we present in Fig. 4 representative TEM images of the samples processed at $523 \mathrm{~K}$ during the CCAE. The TEM observations suggest again that dynamic recrystallization takes place during the extrusion, and that the shearing stress affects microstructure significantly. Typical microstructures of the alloys before being sheared during the extrusion are shown in Figs. 4(a) and 4(b), where one can see a large number of heterogeneously distributed dislocations, together with substructures and cell walls. Further examination reveals that most of the grain boundaries turn out to be fully defined subgrain boundaries and high angle grain boundaries, consistent with the observation on AZ31 alloy processed by the ECAE. ${ }^{15)}$ At the shearing zone shown in Fig. 4(c), some grains are deformed severely, having a few dislocations or twins in their interior, which might be due to the noticeable strains imposed by the CCAE. The grain size decreases further and the high angle grain boundaries become more pronounced at this stage, indicating occurrence of dynamic recovery and recrystallization. Figure 4(d) presents microstructure image of completely deformed sample after the CCAE. The recrystallized structure can be seen in the way similar to the results reported by Chang et al. ${ }^{19)}$ and Janecek 

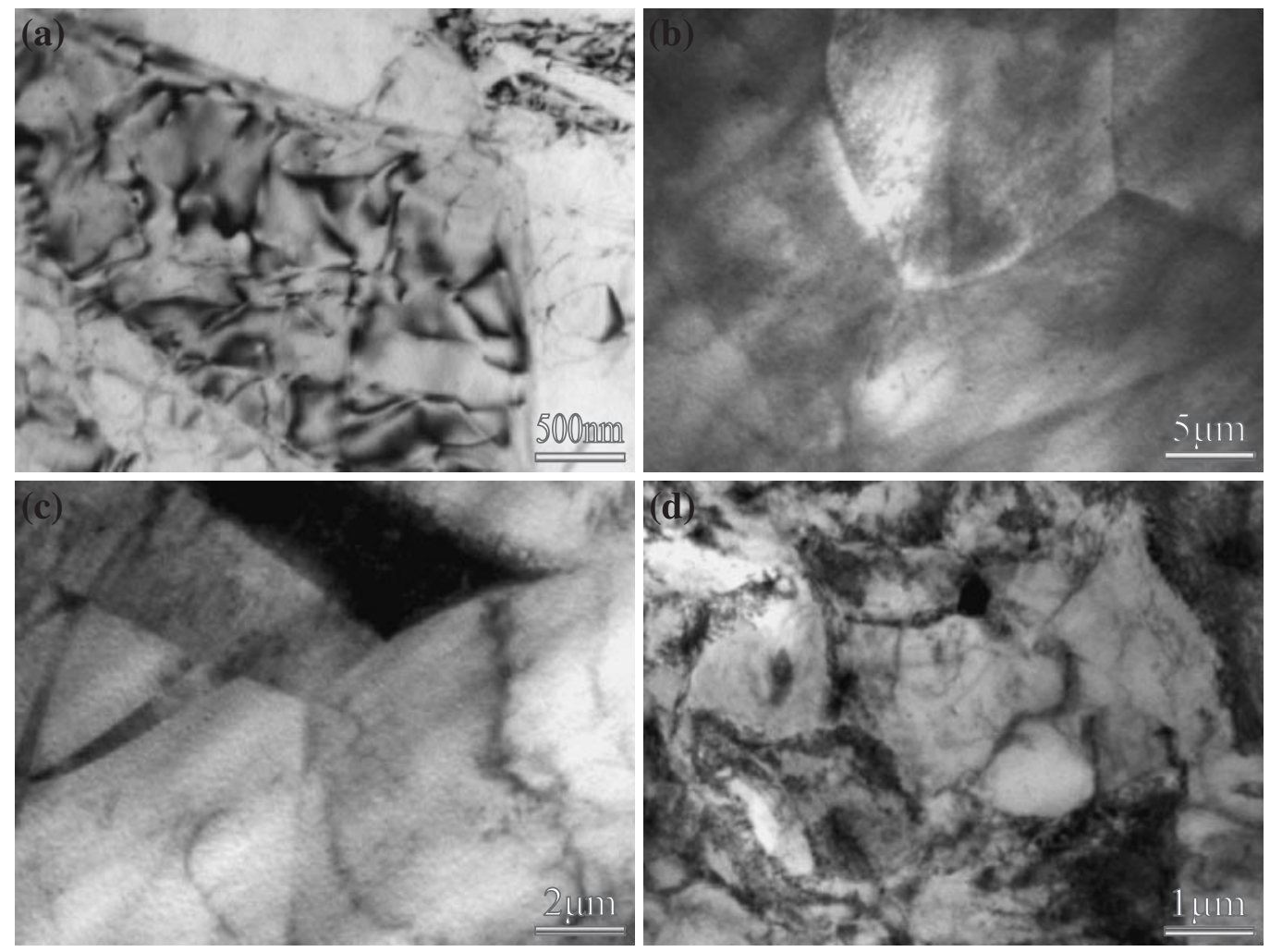

Fig. 4 Representative TEM photographs showing microstructure changes in the specimen during the CCAE process at $523 \mathrm{~K}$ : (a) before being sheared, (b) enlarged region of (a), (c) at shearing zone, and (d) after deformation imposed by the CCAE.

et al. ${ }^{13)}$ Moreover, one can also identify from this figure trace of severe deformation process and grain subdivision.

The grain refinement and microstructure change during the CCAE processed at $523 \mathrm{~K}$ as well as other temperatures can be attributed to the grain subdivision and dynamic recrystallization induced by the drastic extrusion. As the specimen is on its way to and passes through the intersection of die channels, severe plastic deformation is imposed, resulting in generation and accumulation of dislocations and twins, in particular in the coarse grains. The tangled dislocations of high density arrange themselves to form cell structures and walls and finally evolve into sub-grains, thereby increasing grain boundary energy dramatically. Such grains with nonequilibrium boundaries could store sufficient energy so as to experience dynamic recrystallization during the deformation process. The recrystallization takes place preferably where the defect density is high. The net consequence is a reduction of grain size owing to the recrystallization process and also the generation of high angle boundaries after dislocation rearrangement.

\subsection{Micro-hardness and compressive deformation be- havior}

The variation in grain size and texture at different processing temperatures might affect mechanical properties. To test this effect, we first measured micro-hardness $\left(H_{\mathrm{V}}\right)$ for the AZ31 alloys processed at various temperatures. As seen in Fig. 5, the micro-hardness increases gradually with decreasing processing temperature, which is due to the grain refinement by lowering temperature (Fig. 3). This agrees with the trend displayed in the AZ31 alloys deformed by the

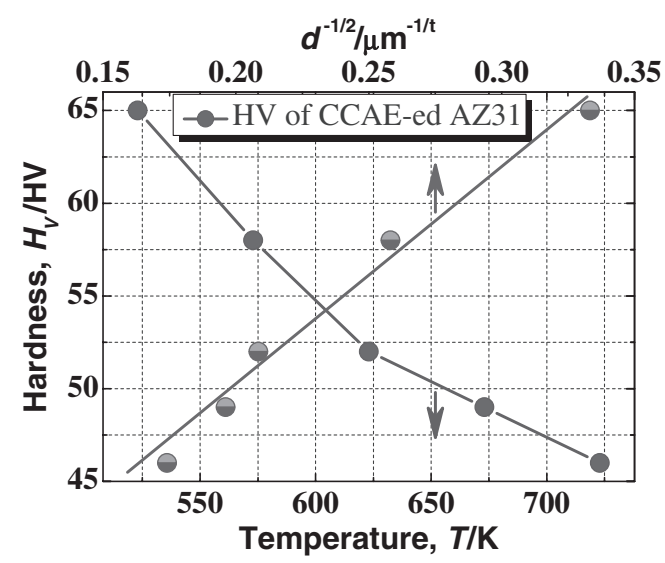

Fig. 5 Changes of micro-hardness of the CCAE-processed AZ31 alloys as a function of processing temperature (bottom $x$ axis) and of $d^{-1 / 2}$ (Top $x$ axis). The values of grain size correspond to those in Fig. 3.

ECAE at different temperatures. ${ }^{21)}$ In addition, the microhardness value of the alloy after the CCAE at $523 \mathrm{~K}, 65 \mathrm{HV}$, is comparable to the value of $62 \mathrm{HV}$ for the AZ31 alloy pressed by 4 repetitive ECAEs at $523 \mathrm{~K}^{21)}$ and that of $66 \mathrm{HV}$ at $493 K^{19)}$ Further, one can also see from Fig. 5 that the micro-hardness $\left(H_{\mathrm{V}}\right)$ and average grain size $(d)$ follow approximately the Hall-Petch relationship ${ }^{22)}$ expressed by $H_{\mathrm{V}}=H_{0}+K_{\mathrm{H}} d^{-1 / 2}$, where $H_{0}$ and $K_{\mathrm{H}}$ are material constants and determined to be 26.3 and 118.4, respectively, for the CCAE-processed AZ31 alloy. This means that additional strengthening is a direct consequence of grain refinement. Such similar grain size dependence of mechanical properties 


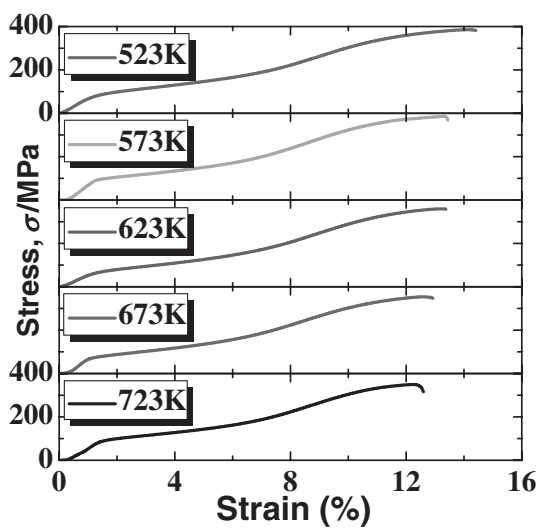

Fig. 6 Compressive stress vs. strain curves at room temperature for the AZ31 samples processed by the CCAE at different temperatures ranging from 523 to $723 \mathrm{~K}$.

has also been observed in the AZ31 alloy subjected to other processing techniques ${ }^{22)}$ and in the $\mathrm{Mg}$ alloy with low $\mathrm{Al}$ content $(0.9 \text { mass } \%)^{20)}$

Next, we investigated room-temperature compressive stress-strain characteristics of the AZ31 using a load parallel to the extrusion direction. Figure 6 shows the compressive stress-strain curves of the samples after the CCAE at various temperatures. The fundamental shapes of the curves at each temperature do not differ from each other noticeably, exhibiting an initial sharp increase of hardening and a subsequent gradual increase until close to the peak stress and fracture. This is similar to the typical compressive stressstrain curve of an ECAE-processed AZ31 alloy ${ }^{23)}$ but somewhat deviates from that of the AZ31 alloy imposed by hot extrusion processing, ${ }^{24)}$ which shows clearly a yielding plateau. This slight deviation may be ascribed to the different microstructures, where in the hot-extrusion case, a large number of deformation twins were found. Another point to be noted in Fig. 6 is that the curves show no peak-like flow bumps, which is obviously due to the quite homogenous microstructure (Fig. 3). In addition, both the yield stress and fracture strain decrease slightly as the processing temperature increases.

Finally, we computed the $0.2 \%$ proof stress (yield stress), ultimate compressive strength (UCS), and compressive ratio (plastic deformation up to the point of maximum load) from the above stress-strain curves to further analyze the influence of processing temperature on mechanical properties. As seen in Fig. 7, all of the three quantities increase with lowering processing temperature, which is due to the decreasing grain size (Fig. 3). The difference among them is that the two strengths decrease gradually in the entire temperature region while the compressive ratio decreases sharply from 523 to $573 \mathrm{~K}$ but smoothly afterwards. This is because besides the grain size, the mechanical properties can also be possibly influenced by the crystallographic texture. ${ }^{25,26)}$ Previous studies have suggested that most of the basal planes are inclined to be $45^{\circ}$ from the extrusion direction along the shear plane below processing temperature of $523 \mathrm{~K}$ while tend to be parallel to the extrusion direction above $573 \mathrm{~K}^{27}$ ) This formation of $45^{\circ}$ angle below $523 \mathrm{~K}$ causes the basal planes to slip easier due to the maximum imposed shear

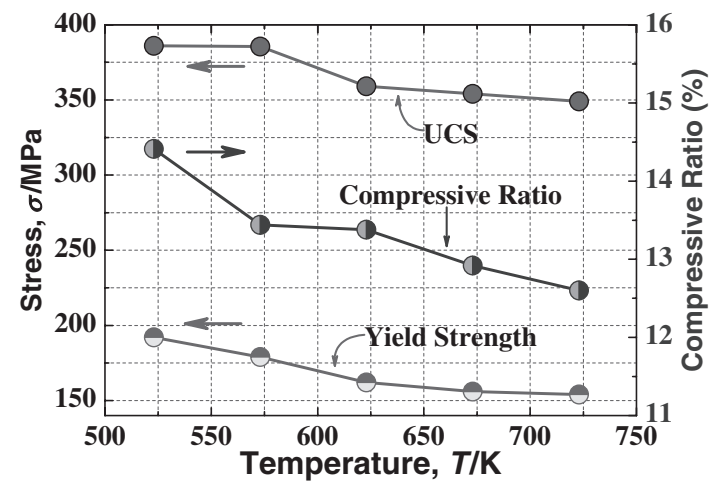

Fig. 7 The $0.2 \%$ proof stress (yield stress), ultimate compressive strength (UCS), and compressive ratio of the AZ31 alloys after the CCAE at various processing temperatures. Compressive ratio is represented by the right $y$ axis.

force, which as a result, retards the increase of strength originated from the largely decreased grain size at $523 \mathrm{~K}^{28)}$ Further, by comparing our data with available reports, we found that our yield stress of $192 \mathrm{MPa}$ at $523 \mathrm{~K}$ is larger than that of $160 \mathrm{MPa}^{29)}$ and $130 \mathrm{MPa}^{30)}$ obtained by 6 repetitive ECAEs, and that of $160 \mathrm{Mpa}^{24)}$ by the hot extrusion. Additionally, the UCS of $386 \mathrm{MPa}$ and compressive ratio of $14.4 \%$ at $523 \mathrm{~K}$ are also comparable to corresponding values of $370 \mathrm{MPa}$ and $15 \%$ for the hot-extruded AZ31. ${ }^{24)}$

\section{Conclusions}

We have applied a change-channel angular extrusion technique to $\mathrm{Mg}$ alloy $\mathrm{AZ31}$ and investigated in details the microstructure evolution and mechanical properties. In particular, we have focused on the effect of processing temperatures. We have found that microstructures of the AZ31 alloys subjected to the CCAE at each temperature are refined considerably compared to those of as-cast alloys. The mean grain size decreases monotonously with lowering processing temperature, resulting in enhanced micro-hardness, yield stress, ultimate compressive strength, and compressive ratio. Careful examination of the microstructure evolution reveals that dynamic recrystallization occurs during the CCAE deformation at various temperatures, which is responsible for the grain refinement. The microhardness and mean grain size follow basically the Hall-Petch relationship, suggesting that grain refinement play a relevant role in increasing hardening. Moreover, we have also found that microstructure and mechanical properties of the AZ31 alloy imposed by a single CCAE process can be comparable to those of the alloy processed by the ECAE with several passes. The present results suggest that the CCAE is also an effective way for further improving mechanical properties of $\mathrm{Mg}$ alloys.

\section{Acknowledgements}

This work was supported in part by the National 973 Major Project of China, "The Key Fundamental Problem of Processing and Preparation for High Performance Magnesium Alloy”, under Grant No. 2007CB613700. 


\section{REFERENCES}

1) B. L. Mordike and T. Ebert: Mater. Sci. Eng. A 302 (2001) 37-45.

2) H. Friedrich and S. Schumann: J. Mater. Proc. Tech. 117 (2001) 276-281.

3) J. A. del Valle, M. T. Perez-Prado and O. A. Ruano: Mater. Sci. Eng. A 355 (2003) 68-78.

4) K. Ishikawa, H. Watanabe and T. Mukai: J. Mater. Sci. 40 (2005) 1577-1582.

5) T. Liu, Y. D. Wang, S. D. Wu, R. L. Peng, C. X. Huang, C. B. Jiang and S. X. Li: Scr. Mater. 51 (2004) 1057-1061.

6) D. K. Xu, L. Liu, Y. B. Xu and E. H. Han: Scr. Mater. 57 (2007) 285288

7) S. Y. Chang, H. Tezuka and A. Kamio: Mater. Trans. 38 (1997) 526-535.

8) M. Furukawa, Z. Horita, M. Nemoto and T. G. Langdon: Mater. Sci. Eng. A 324 (2002) 82-89.

9) R. Z. Valiev: Adv. Eng. Mater. 5 (2003) 296-300.

10) D. H. Shin, Y. S. Kim and E. J. Lavernia: Acta Mater. 49 (2001) 2387-2393.

11) Y. Iwahashi, J. Wang, Z. Horita, M. Nemoto and T. G. Landon: Scr. Mater. 35 (1996) 143-146.

12) V. M. Segal: Mater. Sci. Eng. A 197 (1995) 157-164.

13) M. Janecek, M. Popov, M. G. Krieger, R. J. Hellmig and Y. Estrin: Mater. Sci. Eng. A 462 (2007) 116-120.

14) C. W. Su, L. Lu and M. O. Lai: Mater. Sci. Tech. 23 (2007) 290296.

15) L. Jin, D. Lin, D. Mao, X. Zeng and W. Ding: Mater. Lett. 59 (2005)
2267-2270.

16) Y. Yoshida, L. Cisar, S. Kamado and Y. Kojima: Mater. Trans. 44 (2003) 468-475.

17) W. J. Kim, J. B. Lee, W. Y. Kim, H. T. Jeong and H. G. Jeong: Scr. Mater. 56 (2007) 309-312.

18) H. K. Lin, J. C. Huang and T. G. Langdon: Mater. Sci. Eng. A 402 (2005) 250-257.

19) S. Y. Chang, S. W. Lee, K. M. Kang, S. Kamado and Y. Kojima: Mater. Trans. 45 (2004) 488-492.

20) A. Yamashita, Z. Horita and T. G. Langdon: Mater. Sci. Eng. A 300 (2001) 142-147.

21) S. H. Kang, Y. S. Lee and J. H. Lee: J. Mater. Proc. Tech. 201 (2008) 436-440.

22) W. J. Kim and Y. K. Sa: Scr. Mater. 54 (2006) 1391-1395.

23) K. Mueller and S. Mueller: J. Mater. Proc. Tech. 187-188 (2007) $775-779$.

24) Y. N. Wang and J. C. Huang: Acta Mater. 55 (2007) 897-905.

25) S. R. Agnew, J. A. Horton, T. M. Lillo and D. W. Brown: Scr. Mater. 50 (2004) 377-381.

26) M. Mabuchi, K. Ameyama, H. Iwasaki and K. Higashi: Acta Mater. 47 (1999) 2047-2057.

27) W. J. Kim, S. I. Hong, Y. S. Kim, S. H. Min, H. T. Jeong and J. D. Lee: Acta Mater. 51 (2003) 3293-3307.

28) X. N. Du, S. M. Yin, S. C. Liu, B. Q. Wang and J. D. Guo: J. Mater. Res. 23 (2008) 1570-1577.

29) K. Xia, J. T. Wang, X. Wu, G. Chen and M. Gurvan: Mater. Sci. Eng. A 410-411 (2005) 324-327.

30) W. J. Kim and H. T. Jeong: Mater. Trans. 46 (2005) 251-258. 